\title{
Murine CD146 is widely expressed on endothelial cells and is recognized by the monoclonal antibody ME-9F1
}

\author{
Arnhild Schrage · Christoph Loddenkemper · Ulrike Erben • Uta Lauer • \\ Gert Hausdorf · Peter R. Jungblut · Judith Johnson • Percy A. Knolle • Martin Zeitz • \\ Alf Hamann · Katja Klugewitz
}

Accepted: 7 January 2008 / Published online: 24 January 2008

(C) Springer-Verlag 2008

\begin{abstract}
The endothelium plays an important role in the exchange of molecules, but also of immune cells between blood and the underlying tissue. The endothelial molecule S-Endo 1 antigen (CD146) is preferentially located at endothelial junctions and has been claimed to support endothelial integrity. In this study we show that the monoclonal antibody ME-9F1 recognizes the extracellular portion of murine CD146. Making use of ME-9F1 we found CD146 highly expressed and widely spread on endothelial cells in the analyzed murine tissues. In contrast to humans that express CD146 also on T cells or follicular dendritic cells, murine CD146 albeit at low levels was only found on a subset of NK1.1 $1^{+}$cells. The antibody against murine CD146 is
\end{abstract}

A. Schrage $\cdot$ U. Erben $\cdot$ M. Zeitz $\cdot$ K. Klugewitz $(\bowtie)$

Gastroenterologie, Charité Campus, Benjamin Franklin,

Hindenburgdamm 30, 12203 Berlin, Germany

e-mail: katja.klugewitz@charite.de

C. Loddenkemper

Institut für Pathologie, Charité Campus Benjamin Franklin,

Hindenburgdamm 30, 12203 Berlin, Germany

U. Lauer · G. Hausdorf · A. Hamann

Rheumatologie, Charité Campus Mitte,

Schumannstr. 21/22, 10117 Berlin, Germany

P. R. Jungblut

Max-Planck-Institut für Infektionsbiologie,

Schumannstr. 21/22, 10117 Berlin, Germany

J. Johnson

Institut für Immunologie, Ludwig-Maximilians-Universität,

Goethestr. 29-31, 80336 Munich, Germany

P. A. Knolle

Institut für Molekulare Medizin und Experimentelle Immunologie,

Rheinische Friedrich-Wilhelms-Universität,

Sigmund Freud Str. 25, 53105 Bonn, Germany useful for immunomagnetic sorting of primary endothelial cells not only from the liver but from various other organs. In vitro, no evidence was seen that the formation and integrity of endothelial monolayers or the transendothelial migration of $\mathrm{T}$ cells was affected by antibody binding to CD146 or by crosslinking of the antigen. This makes the antibody ME-9F1 an excellent tool especially for the ex vivo isolation of murine endothelial cells intended to be used in functional studies.

Keywords Antibody ME-9F1 - Endothelial cells · NK cells · Tissue distribution of murine CD146

\begin{tabular}{|c|c|}
\hline Abbreviation & \\
\hline AcLDL & Acetylated low density lipoprotein \\
\hline CXCL12 & CXC-chemokine ligand 12 \\
\hline FITC & Fluorescein isothiocyanate \\
\hline LSEC & Liver sinusoidal endothelial cells \\
\hline LYVE-1 & $\begin{array}{l}\text { Lymphatic vessel endothelial hyaluronic } \\
\text { acid receptor }\end{array}$ \\
\hline mab & Monoclonal antibody \\
\hline MALDI-MS & $\begin{array}{l}\text { Matrix-assisted laser-desorption } \\
\text { ionization mass spectrometry }\end{array}$ \\
\hline NK & Natural killer cell \\
\hline TCR & $\mathrm{T}$ cell receptor \\
\hline VE-cadherin & Vascular endothelial cadherin \\
\hline
\end{tabular}

\section{Introduction}

The vascular endothelium forms a continuous monolayer on the inner surface of the vessel wall and acts as a barrier between circulating blood and underlying tissues. Concomitantly, it functions as a filter and establishes communication between both compartments (Bazzoni 2006). 
Several adhesion molecules are currently used as endothelial cell markers. The endothelium specific vascular endothelial cadherin (VE-cadherin, CD144) is restricted to interendothelial adherence junctions and plays a role for paracellular permeability and maintenance of cell polarity (Gao et al. 2000; Gotsch et al. 1997; Lampugnani et al. 1995). CD31, platelet endothelial cell adhesion molecule 1 (Piali et al. 1993; Vecchi et al. 1994) is additionally found on leukocytes. Its homophilic interaction between endothelium and leukocytes is described during diapedesis (Bogen et al. 1992). CD105, endoglin, is expressed on angiogenic endothelial cells and serves as a receptor for TGF $\beta$ (Duff et al. 2003). Endothelial cell-selective adhesion molecule (ESAM) co-localizes with cadherin/catenin proteins along the lateral membrane of endothelial cells and is required for the extravasation of neutrophils, but not lymphocytes, into inflamed tissues (Hirata et al. 2001; Ishida et al. 2003; Wegmann et al. 2006). CD146, also known as S-Endo 1 antigen, is a structural component of endothelial junctions (Bardin et al. 1996b). It was initially found on melanoma cells, thus formerly named MUC18 or melanoma cellular adhesion molecule (Lehmann et al. 1989; Shih 1999). CD146 has been reported to be functionally relevant for endothelial cell adhesion and angiogenesis (Solovey et al. 2001; Yan et al. 2003). So far virtually all previous studies focused on CD146 in humans. In the mouse only little is known on the functional relevance of CD146, e.g. in murine disease models.

In the present study we describe the monoclonal antiendothelial cell antibody ME-9F1 to recognize murine CD146. By use of ME-9F1 we determined the tissue distribution of CD146 in the mouse. Furthermore, the antibody was shown to be useful for the identification and isolation of endothelial cells from various murine tissues.

\section{Materials and methods}

\section{Antibodies}

The hybridoma ME-9F1 was generated by standard fusion technique after immunization of DA rats with the endothelial cell line TME-3H3 as previously described (Duijvestijn et al. 1987; Galfre and Milstein 1981; Harder et al. 1991). Anti-human CD146 (MUCBA18.3) directed against the cytoplasmic domain of human CD146 and being crossreactive to mouse was produced as described elsewhere (Lehmann et al. 1989). Anti-VE-cadherin (11D4.1) was a gift from Dietmar Vestweber, Max-Planck-Institut für Molekulare Medizin, Münster, Germany. Anti-CD4 (GK1.5), anti-CD31 (3E2) and anti-Fc $\gamma$ receptor II/III (2.4G2/75) were obtained from the Deutsches RheumaForschungszentrum, Berlin, Germany. Meca32, anti- $\alpha 2-$ integrin (DX5), anti-NK1.1 (PK136), anti-T cell receptor (TCR) $\beta$ (H57-597) and all fluorescent reagents were from BD Biosciences, Heidelberg, Germany. Rat IgG and rabbitanti-rat antibody were from Dako Cytomation, Hamburg, Germany.

Mice

Female C57BL/6 mice were obtained from the Bundesamt für Risikobewertung, Berlin, Germany. CD146 ${ }^{-/-}$mice were bred at the Institut für Immunologie, München, Germany. $\mathrm{CD} 146^{-1-}$ mice appear healthy, are fertile and breed at normal ratios. Animal care was performed according to the criteria published by the National Institutes of Health, Bethesda, MD.

\section{Endothelioma cell lines}

Murine skin derived endothelioma SEND and brain endothelioma bEND5 (Rohnelt et al. 1997; Wagner and Risau 1994; Williams et al. 1989) were a gift from Britta Engelhardt, Bern, Switzerland. Murine mesenteric lymph node derived endothelioma mlEND1 (Sorokin et al. 1994) were provided by Rupert Hallmann, Münster, Germany. Cells were cultured in Dulbecco's minimal essential medium (Cambrex Bio Science, Verviers, Belgium), supplemented with $10 \%$ fetal calf serum (Invitrogen, Karlsruhe, Germany) and harvested by detachment with Accutase (PAA Laboratories, Pasching, Austria). In some experiments cells were incubated with $50 \mu \mathrm{g} / \mathrm{ml} \mathrm{ME}-9 \mathrm{~F} 1$ or isotype matched control antibody while growing to confluence. Phase contrast pictures were taken after 24 and $48 \mathrm{~h}$ from three different areas with a Leica DM IRE2 microscope (Leica Microsystems, Wetzlar, Germany).

\section{Purification and identification of the ME-9F1 antigen}

Detached sEND were homogenized in $10 \mathrm{mM}$ Tris/Chloride, $\mathrm{pH}$ 7.0, $250 \mathrm{mM}$ sucrose (Merck, Darmstadt, Germany). Membranes were isolated by sequential centrifugation and solubilized by sonication and stirring on ice for $1 \mathrm{~h}$ in detergent buffer containing $100 \mathrm{mM}$ Tris/Chloride, $\mathrm{pH} 7.0 ; 100 \mathrm{mM} \mathrm{NaCl}$ and $1.2 \%$ 1-O- $n$-Octyl-beta-Dglucopyranoside (Roche, Mannheim, Germany). For immunoadsorption the monoclonal antibody (mab) ME-9F1 or isotype matched rat $\mathrm{IgG}$ were coupled to activated $\mathrm{CH}$ Sepharose 4B (Amersham Pharmacia Biotech, Freiburg, Germany) according to the standard procedure given by the manufacturer. After pre-adsorption with rat IgG-Sepharose, the solubilized membrane fraction was incubated with ME9F1-Sepharose. Adsorbed proteins were eluated by heating for $10 \mathrm{~min}$ at $90^{\circ} \mathrm{C}$ in SDS-PAGE sample buffer and separated on a SDS-10\% PAGE under reducing conditions. After 
staining with Coomassie brilliant blue-R250 (Serva, Heidelberg, Germany) the protein band was excised and analyzed by matrix-assisted laser-desorption ionization mass spectrometry (MALDI-MS) in a 4700 Proteomics Analyzer (Applied Biosystems, Framingham, USA). The peptides of five MS peaks were fragmented and further analyzed by MS/MS. A Mascot search was performed in the Swiss-Prot database (Sprot 20060124) with the following restrictions: Variable modifications: N-Acetyl (Protein), Oxidation (M), Propionamide (C), Pyro-glu (N-term Q); Cleavage by Trypsin/P: cuts C-term side of KR; Mass values: monoisotopic; Protein Mass: Unrestricted; Peptide Mass Tolerance: \pm 30 ppm; Fragment Mass Tolerance: $\pm 0.3 \mathrm{Da}$; Max Missed Cleavages: 1 . The protein was considered as identified if the probability score was higher than 60 and the sequence coverage higher than $30 \%$.

For Western blot analysis $150 \mu \mathrm{g}$ protein from lung lysate from wild type or $\mathrm{CD} 146^{-1-}$ mice were separated on a SDS-8\% PAGE under reducing conditions, transferred to nitrocellulose (Schleicher \& Schüll, Dassel, Germany), incubated with ME-9F1 or MUCBA18.3 and peroxidase anti-mouse Ig (Lehmann et al. 1989). Bound antibodies were visualized by the chemiluminiscense substrate Western Lightning (Perkin Elmer, Rodgau-Jügesheim. Germany).

Immunohistochemistry and immunofluorescence microscopy

For immunostaining, $4 \mu \mathrm{m}$-sections of formalin-fixed, paraffin-embedded tissues were cut, deparaffinized and subjected to a heat-induced epitope retrieval step. Sections were immersed in sodium citrate buffer solution at $\mathrm{pH} 6.0$ and heated in a high-pressure cooker for $2 \mathrm{~min}$. Slides were rinsed in cool running water, washed in Tris-buffered saline (pH 7.4), treated with a biotin blocking agent (Dako, Glostrup, Denmark) and incubated with the primary antibody ME-9F1 $(5 \mu \mathrm{g} / \mathrm{ml})$ followed by biotinylated rabbit anti-rat antibody and the streptavidine-conjugated alkaline phosphatase kit using Fast Red as chromogen (both from Dako). Negative controls were performed by omitting the primary antibody.

For double immunofluorescence labeling, snap-frozen material was used for ME-9F1/CD31 and paraffin blocks for ME-9F1/lymphatic vessel endothelial hyaluronic acid receptor (LYVE)-1 staining. Sections were incubated with ME-9F1 followed by Alexa Fluor 555-conjugated anti-rat antibody (1:100; Invitrogen, Carlsbad, CA, USA), washed three times and incubated with fluorescein isothiocyanate (FITC)-conjugated anti-CD31 or rabbit polyclonal antiLYVE-1 antibody (1:1000; Biomol, Hamburg, Germany) followed by Alexa Fluor 488-conjugated anti-rabbit antibody (1:100; Invitrogen). Nuclei were counterstained with
DAPI (1:1500; Roche, Mannheim, Germany) and mounted in Fluoromount-G (Southern Biotech, Birmingham, Alabama, USA). Negative controls were performed by omitting the primary antibodies. Images were acquired using a fluorescence microscope (AxioImager Z1) equipped with a CCD camera (AxioCam MRm) and processed with Axiovision software (Carl Zeiss MicroImaging GmbH, Carl Zeiss AG, Oberkochen and Jena, Germany).

\section{Flow cytometry}

For flow cytometric analysis, single cell suspensions blocked with $10 \mu \mathrm{g} / \mathrm{ml}$ anti-Fc $\gamma$ receptor II/III and rat IgG were incubated with fluorochrome-conjugated antibodies or with biotinylated antibodies in conjunction with fluorochrome-conjugated streptavidine.

Ex vivo cell isolation and sorting of endothelial cells from various murine organs

Spleens were disrupted and passed through a fine mesh to obtain single cell suspensions. Hearts, lungs, kidneys and livers were rinsed and digested with collagenase VI plus DNase I (Sigma-Aldrich, Steinheim, Germany) as previously described (Klugewitz et al. 2002). Non-parenchymal cells were further enriched by one-step density gradient centrifugation with $26 \%$ Nycodenz (Axis Shields, Oslo, Norway). Endothelial cells were magnetically sorted using ME-9F1 or Meca32 (Miltenyi Biotech, Bergisch Gladbach, Germany). After over night culture non-adherent cells and debris were removed by washing. Endothelial cells were detached with Accutase and used for experiments. In some experiments endothelial cells were incubated over night with $1 \mu \mathrm{g} / \mathrm{ml}$ acetylated low density lipoprotein (AcLDL, Molecular Probes, Leiden, The Netherlands). The nuclei were stained with Hoechst 33342 (Molecular Probes).

\section{Transendothelial migration assay}

BEND5 cells were cultured for 2 days on $5 \mu \mathrm{m}$ pore size transwell plates (Corning, New York, NJ) (Rohnelt et al. 1997). Prior to the assay, cells were pre-incubated with $10 \mu \mathrm{g} / \mathrm{ml}$ mab ME-9F1 or isotype matched control mab for $1 \mathrm{~h}$ or $20 \mathrm{~h}$. In some experiments cells were further incubated with $20 \mu \mathrm{g} / \mathrm{ml}$ rabbit-anti-rat $\mathrm{IgG}$ to crosslink bound anti-CD146 antibody. Pretreated cells were thoroughly washed and the transwells placed into new cavities. Formation of endothelial cell layers was analyzed by quantifying the number of endothelial cells by phase contrast microscopy. Subsequently, transendothelial migration assays were performed as previously described (Siegmund et al. 2005). Briefly, $5 \times 10^{5} \mathrm{~T}$ cells were added to the upper and $10 \mathrm{nM}$ CXC-chemokine ligand 12 (CXCL12) (R\&D Systems, 
Minneapolis, MN, USA) was added to the lower chamber. Transmigrated $\mathrm{T}$ cells were harvested after 90 min incubation. The rate of transmigration was quantified by flow cytometry after staining cells for CD4 and adding Fluoresbrite $^{\mathrm{TM}} 20 \mu \mathrm{m}$ microspheres (Polysciences, Warrington, PA, USA).

\section{Results}

The mab ME-9F1 recognizes murine CD146.

The ME-9F1 antigen was enriched by immunoadsorption from solubilized membranes of endothelial cells and separated by SDS-PAGE. The protein band not seen in the negative control without soluble membrane fraction and after pre-adsorption with rat IgG had a molecular ratio above $97 \mathrm{kDa}$ (Fig. 1a) and was subjected to analysis by MALDIMS (Fig. 1b). A Mascot search from fragmented peptides of five MS peaks analyzed by MS/MS (inset) resulted in the identification of CD146 (Q8R2Y2) with a score of 386, a sequence coverage of $35 \%$ and 24 matched peptides.
The specificity of the mab ME-9F1 for CD146 was confirmed by Western blot analysis of lung protein from wild type and $\mathrm{CD} 146^{-/-}$mice (Fig 1c). Both antibodies MUCBA18.3 and ME-9F1 detected a distinct band corresponding to a molecular ratio of about $113 \mathrm{kDa}$ in wild type, but not in $\mathrm{CD} 146^{-/-}$mice. Thus, we were able to identify CD146 as the target antigen of the mab ME-9F1 raised against endothelial cells.

CD146 is strongly expressed by murine vascular endothelial cells and at lower levels on a subset of NK1.1 $1^{+}$cells

The tissue distribution of murine CD146 was first analyzed by immunohistochemistry using tissue sections of healthy murine organs. Staining was possible on cryopreserved material (data not shown) and on paraffin-embedded sections (Fig. 2). In non-lymphoid tissues, CD146 expression was detected in the endothelial cells of pulmonary arteries, veins and the capillary network of the alveolar walls. It is similarly expressed in the arteries, veins and the glomerular capillaries of the kidney. In the liver, the mab ME-9F1
Fig. 1 Preparation and identification of the ME-9F1 antigen. a SDS-PAGE analysis after immunoadsorption of solubilized membrane fractions of murine endothelioma cells with ME9F1-Sepharose. Eluates of control-Sepharose and of controlSepharose after incubation with membrane fraction (pre-adsorption) served as controls. b Peptide mass fingerprint of the SDSPAGE separated ME-9F1 antigen by MALDI-MS. Inset: MS/ MS spectrum of the peak with the mass of 1016.45. $\mathbf{c}$ Western Blot analysis of lung lysate from wild type or CD146 ${ }^{-/-}$mice after staining with MUCBA 18.3 or ME-9F1 and peroxidase antimouse IgG. The mouse IgG heavy chain served as equal loading control

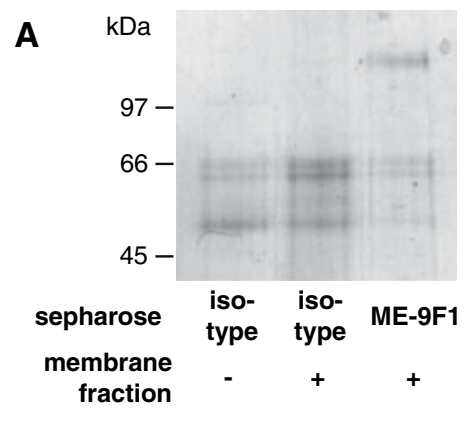

C

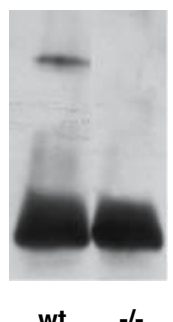

tissue

mab
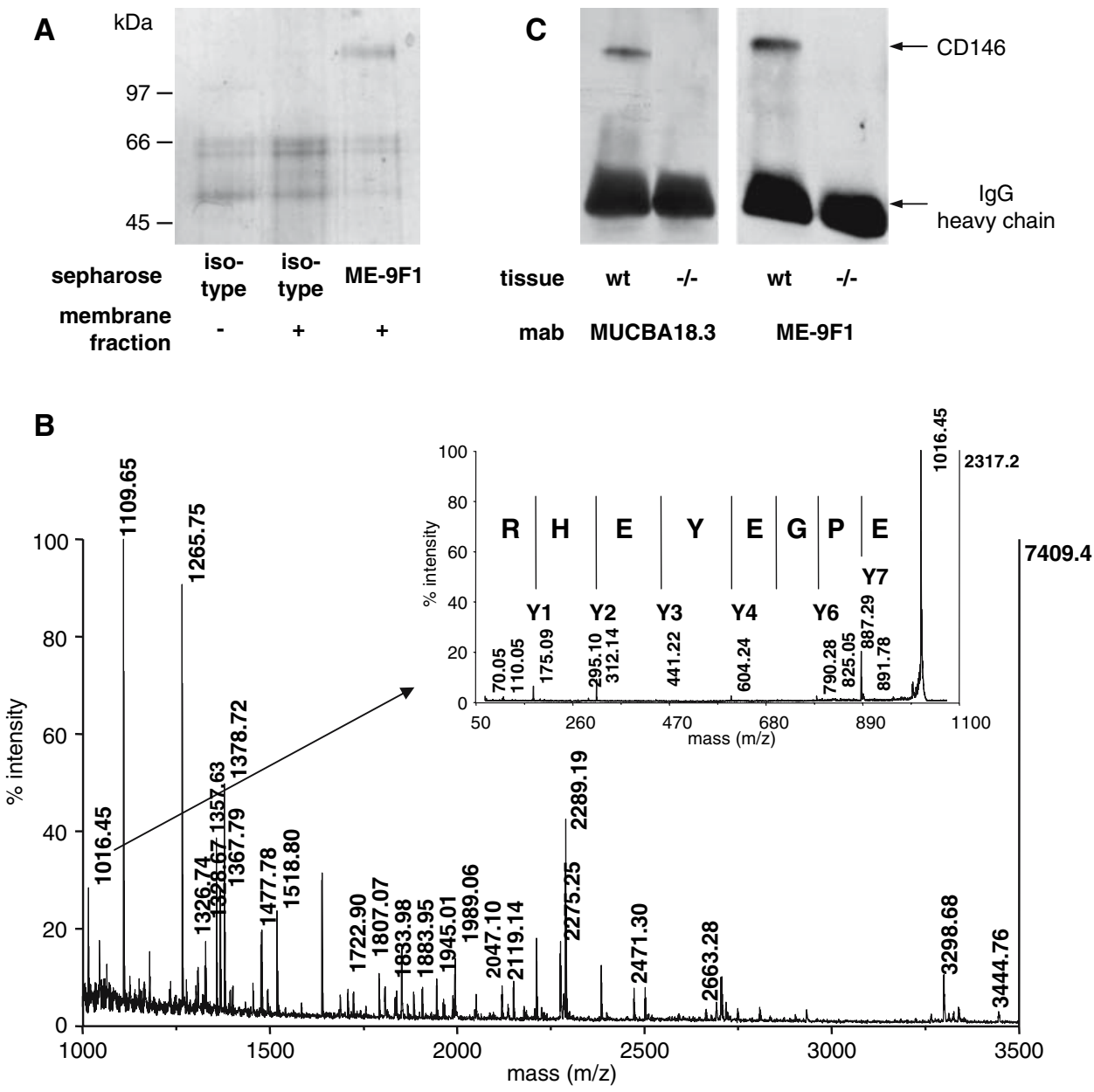
Fig. 2 Tissue distribution of CD146 in murine organs. a Paraffin tissue sections $(4 \mu \mathrm{m})$ were subsequently stained with the mab ME-9F1, biotinylated rabbit anti-rat antibody and streptavidine-alkaline phosphatase and developed with Fast Red, resulting in a red labeling of the endothelial cells of the blood vessels. Original magnification $\times 200$. $\mathbf{b}$ Snap-frozen kidney tissue was stained for CD31 (green) and CD146 (red) (upper panel). Original magnification $\times 200$. Paraffin tissue sections of lymph nodes were stained using a polyclonal antibody against LYVE-1 (green) and ME-9F1 against CD146 (red) (lower panel). Original magnification $\times 100$. Nuclei were counterstained with DAPI (blue). Pictures representative for five mice studied independently

\section{A}

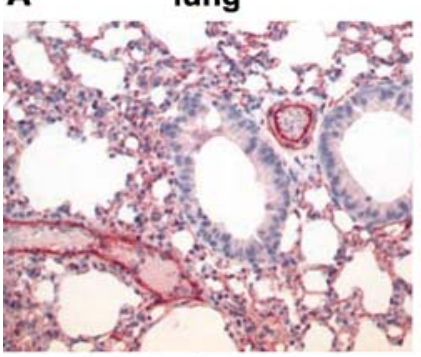

spleen

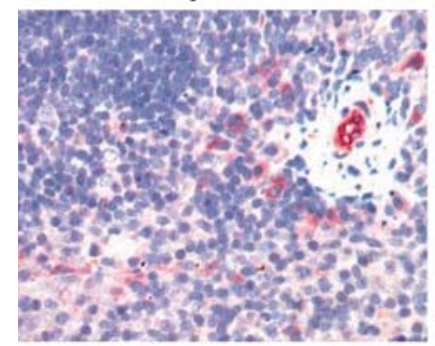

B
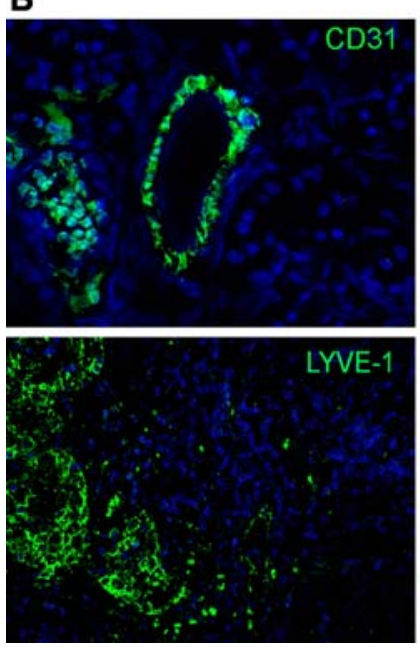

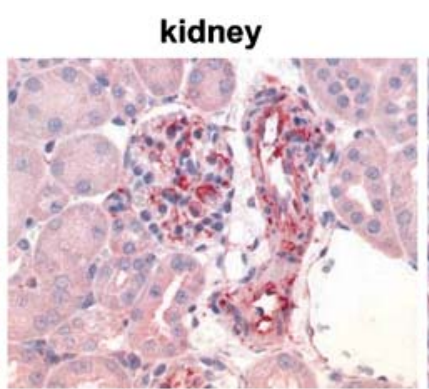

lymph node
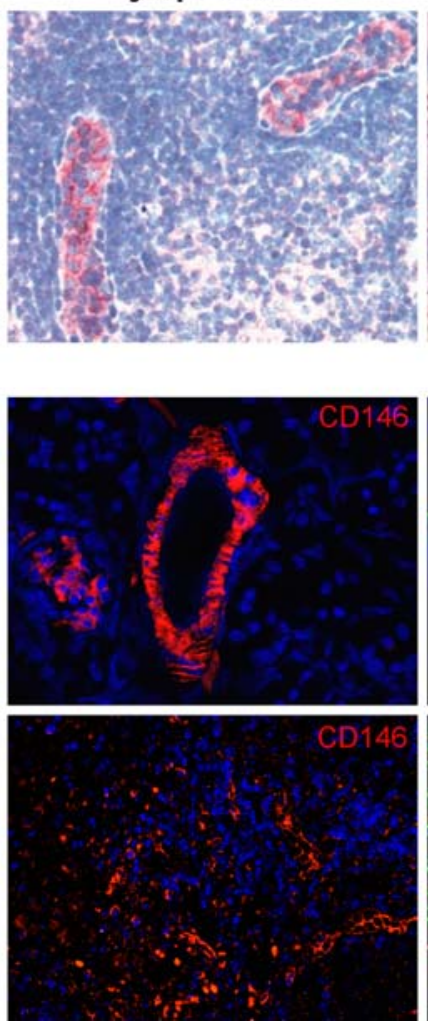

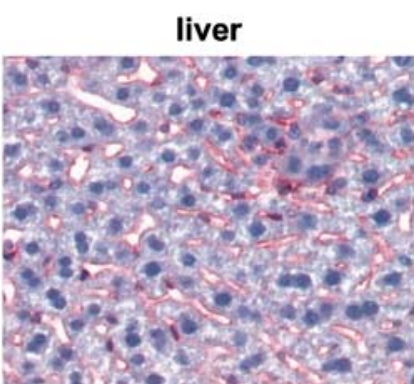

small intestine
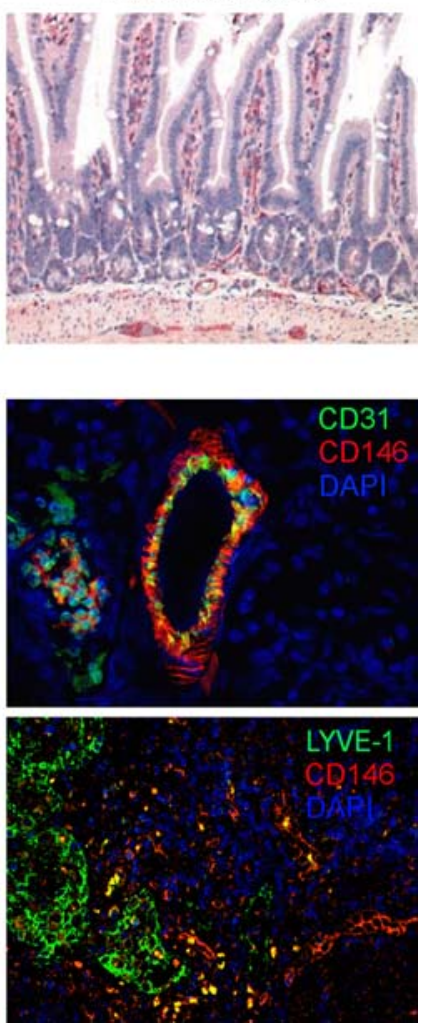

stains larger blood vessels and particularly the liver sinusoidal endothelial cells (LSEC) (Fig. 2a, upper panel). In lymphoid tissues, ME-9F1 marks the endothelium of arterioles and capillaries in the spleen and the high endothelial venules in lymph nodes (Fig. 2a, lower panel) and within Peyer's patches (data not shown). The section of the small intestine shows CD146 expression in the capillary tree of the lamina propria and in the ganglion cells of the myenteric plexus. Homogeneous staining of vascular endothelium was also found in other organs, such as brain, heart and skeletal muscle. Double immunofluorescence labeling showed co-expression of CD31 and CD146 by endothelial cells of an arteriole and an adjacent glomerulum in the kidney (Fig. 2b, upper panel). Afferent lymph vessels in the subcapsular sinus of a lymph node were detected by LYVE-1 expression. In contrast, ME-9F1 did not bind to lymphatic endothelium but instead stained high endothelial venules (Fig. 2b, lower panel). In summary, ME-9F1 binds to vascular, but not to lymphatic endothelium.

In flow cytometry the endothelioma cell lines sEND, bEND5 and to a lesser degree mIEND1 were stained brightly and homogenously by ME-9F1 (Fig. 3a). To analyze CD146 expression on primary endothelial cell populations, cell suspensions from heart, lung, kidney and liver were stained with ME-9F1. Ex vivo-isolated non-lymphoid cell populations are usually heterogeneous, resulting in varying autofluorescence. High levels of CD146 expression tightly correlated to the expression of the other endothelial markers CD31, VE-cadherin and the Meca32 antigen in heart, lung and liver (Fig. 3b). In contrast, kidney endothelial cells defined by the latter markers displayed a lower expression of CD146.

Apart from CD146 ${ }^{\text {high }}$ endothelial cells, we detected a significant population of non-endothelial cells expressing 
Fig. 3 Detection of endothelial and non-endothelial cells using ME-9F1 in flow cytometry. a Endothelioma sEND, bEND5 and mlEND1 were stained with ME-9F1 (bold line) or the respective isotype for negative control (thin line). b Ex vivoisolated cell suspensions from heart, lung, kidney and liver were labeled with ME-9F1, counterstained with anti-CD31, anti-VE-cadherin and Meca32 and analyzed by flow cytometry. c Ex vivo-isolated non-parenchymal liver cells were stained with ME-9F1 in conjunction with mab against the Meca32 antigen, NK1.1, $\alpha 2$-integrin or $\operatorname{TCR} \beta$ and analyzed by flow cytometry. Histograms and dot plots showing lymphoid cells, identified by low forward and side scatter characteristics are representative for at least four independent experiments
A
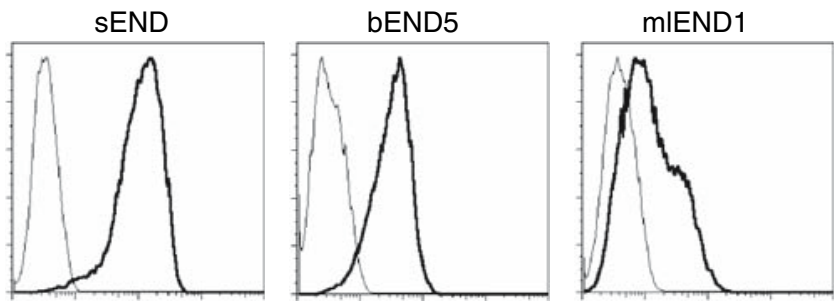

CD146

\section{B}
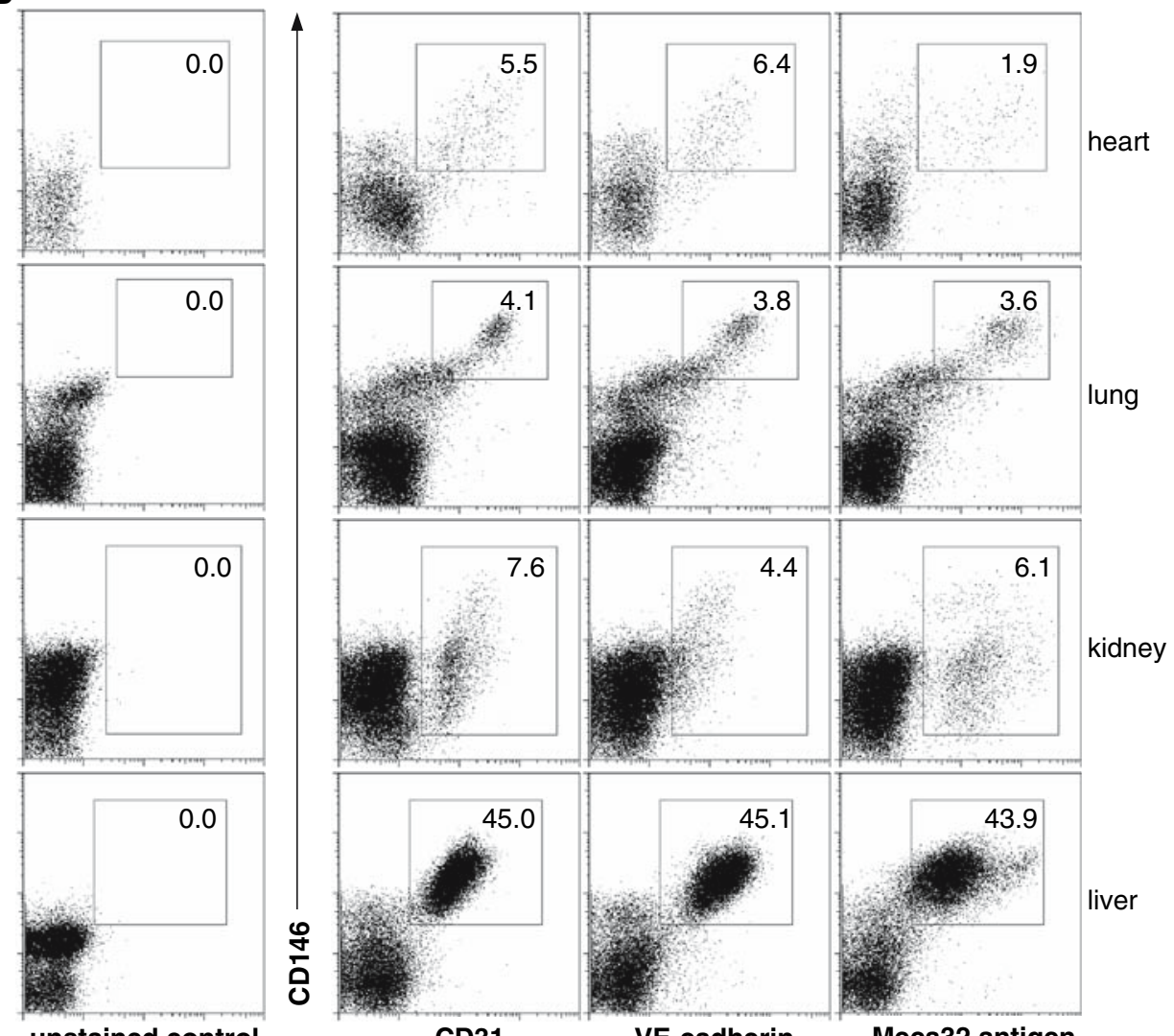

unstained control
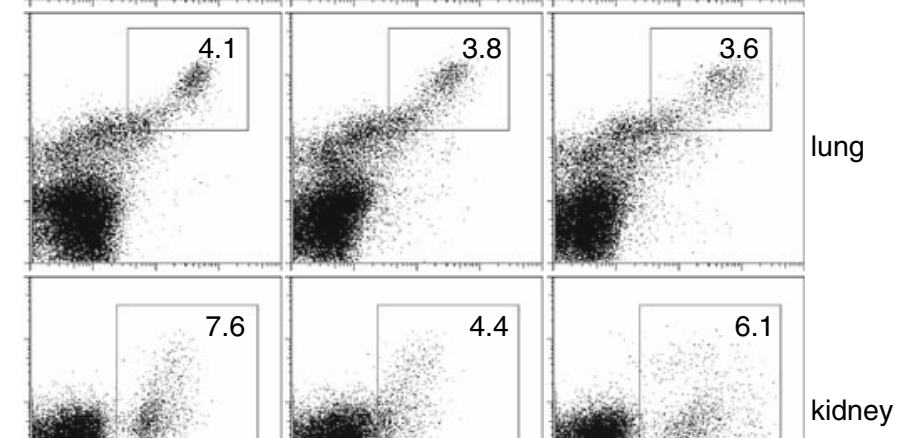

C
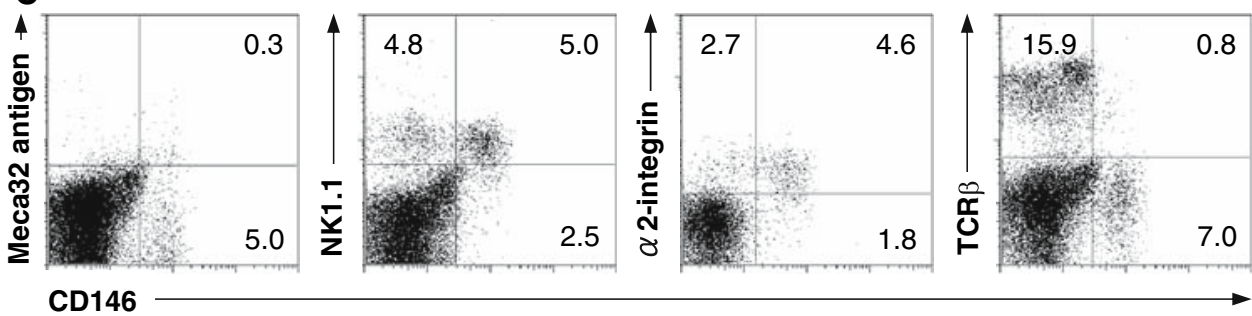

low levels of CD146 in most tissues. We further characterized these cells from spleen (data not shown) and liver (Fig. 3c). They had low forward and side scatter characteristics in flow cytometry typical for lymphoid cells and were negative for endothelial markers, such as for the Meca32 antigen. The majority of these CD146 ${ }^{\text {low }}$ lymphoid cells expressed NK1.1 and $\alpha 2$-integrin but was virtually negative for TCR $\beta$, identifying them as natural killer (NK) cells.
Murine primary endothelial cells from various organs can be immunomagnetically sorted ex vivo due to their CD146 expression

To test if CD146 is also suitable for the enrichment of endothelial cells from different parenchymal organs, ME9F1 was used for positive magnetic cell sorting. We could isolate endothelial cells from lung, kidney and liver 

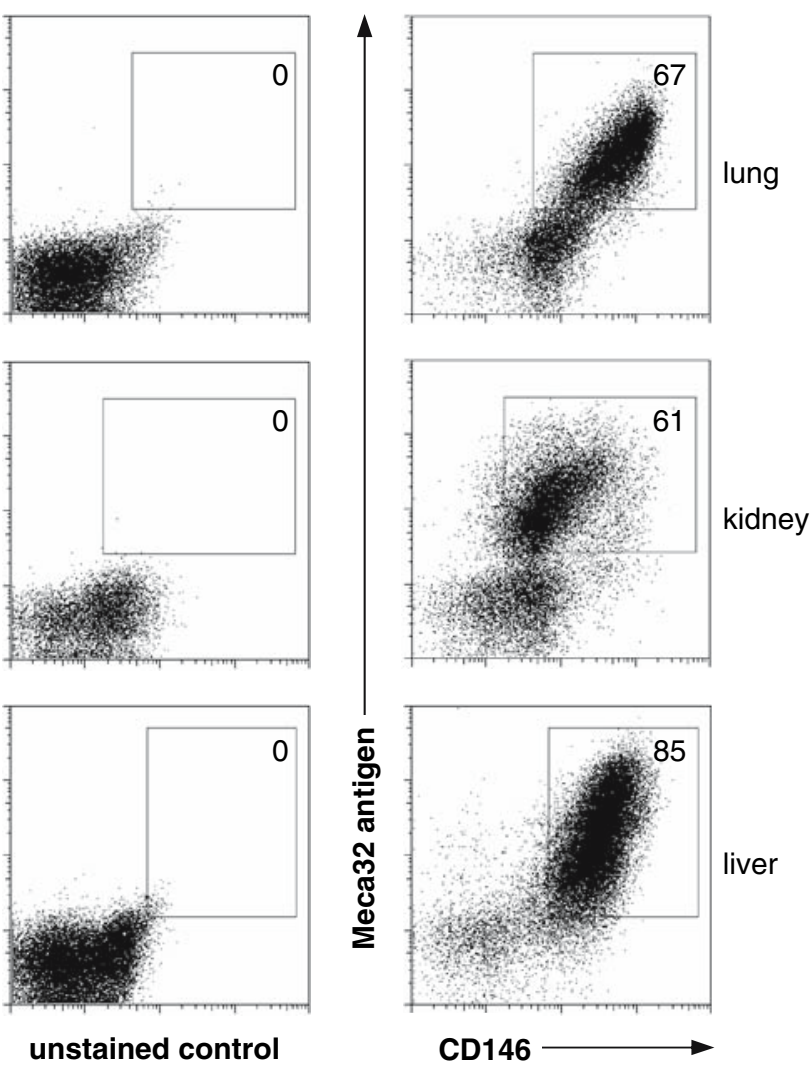

unstained control
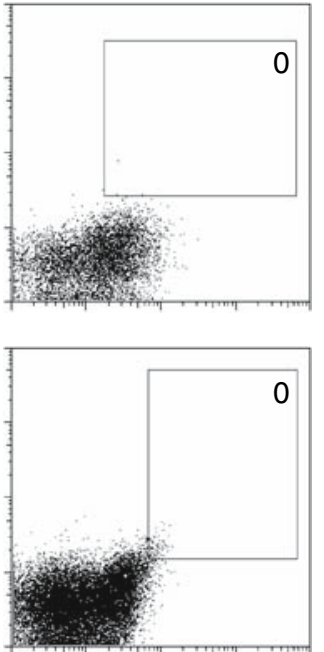

Fig. 4 Enrichment of endothelial cells from various organs by magnetic sorting with ME-9F1. Ex vivo-isolated cells from lung, kidney and liver were subjected to magnetic sorting using ME-9F1. Endothelial cells within the positive fractions were subsequently co-stained with Meca32 and detected by flow cytometry. Dot plots show representative data from 3-8 independent experiments

(Fig. 4). Percentages of endothelial cells from lung and kidney were increased from initially $1-6 \%$ to over $60 \%$, yielding approximately $3 \times 10^{5}$ and $1.5 \times 10^{5}$ endothelial cells per organ, respectively. Magnetic sorting of LSEC resulted in a purity of $80-90 \%$ and a yield of $(2.1 \pm 1.5) \times 10^{6}$ endothelial cells per liver. When organized to monolayers, the cells showed the typical endothelial morphology (Fig. 5a) and efficiently took up AcLDL as shown by fluorescence microscopy (Fig. 5b) and flow cytometry (Fig. 5c). After over night culture the purity of vital LSEC was further increased up to $95-98 \%$. Upon 6 days of in vitro culture LSEC maintained the typical expression pattern of endothelial cell markers including CD146 (Fig. 5d).

ME-9F1 does not affect endothelial cell growth or transendothelial $\mathrm{T}$ cell migration in vitro. For human cells, blocking of CD146 was reported to exert effects on endothelial integrity. We therefore tested whether binding of ME-9F1 might influence the formation and function of an endothelial monolayer. The endothelioma cells mIEND1, bEND5 (data not shown) and sEND (Fig. 6a) incubated with ME-9F1 during culture grew similarly. Cell morphology in the monolayers in the absence or presence of ME-
9F1 was indistinguishable. To address if ME-9F1 affects transendothelial migration of $\mathrm{T}$ cells, bEND5 cells were incubated with ME-9F1 with or without Fc-mediated antibody crosslinking (Fig. 6b). Neither the spontaneous nor the chemokine-induced transendothelial migration of $\mathrm{CD}^{+}$ $\mathrm{T}$ cells as shown for CXCL12 was altered after pre-incubating the endothelial cells with ME-9F1. We conclude that the mab ME-9F1 is not blocking structures of CD146 that are functionally involved in these processes.

\section{Discussion}

CD146 is a transmembrane glycoprotein and belongs to the IgG superfamily of cell adhesion molecules (Sers et al. 1993). In humans, CD146 is described to be expressed on all types of endothelial cells independent of vessel size or site. It is preferentially localized at intercellular endothelial junctions (Bardin et al. 2001,1996a). Human CD146 expression is not completely restricted to endothelial cells. Low levels are also found on melanoma cells (Lehmann et al. 1989; Shih 1999), smooth muscle cells, follicular dendritic cells (Bardin et al. 1996b) and a small subpopulations of activated T cells (Pickl et al. 1997). We identified murine CD146 as the antigen recognized by the mab ME-9F1 by immunoprecipitation and mass spectrometry and confirmed the results by use of CD146 ${ }^{-1-}$ mice. Using ME-9F1, we were able to study the distribution of CD146 in the murine system.

Corresponding to humans, we detected high levels of CD146 expression on endothelial cells of murine vessels throughout the body. We also observed low expression levels of CD146 on non-endothelial cells in several organs of mice. However, in contrast to humans, we did not detect significant CD146 expression in smooth muscle cells of any organ investigated. $\mathrm{T}$ cells and follicular dendritic cells were also $\mathrm{CD} 146^{-}$, as all non-endothelial CD146 ${ }^{\text {low }}$ cells from spleen and liver were $\mathrm{TCR} \beta^{-}$and $\mathrm{FDC}-\mathrm{M} 2^{-}$(G. Wittenburg, personal communication). Since murine $\mathrm{CD}_{146^{+}}$non-endothelial cells from spleen and liver coexpressed NK1.1 and $\alpha 2$-integrin, they appear to represent a distinct subpopulation of NK cells (Yokoyama and Seaman 1993) that are especially abundant in the liver (Crispe 2003; Doherty et al. 1999). Expression on human endothelial and activated $\mathrm{T}$ cells has led to the speculation that CD146 plays a physiological role for leukocyte trafficking (Pickl et al. 1997). It remains to be investigated, if murine CD146 is involved in the migration of NK cells.

Some markers have been proven to be suitable for the detection of endothelial cells, such as CD31, Meca32 antigen, von Willebrand Factor, ESAM or CD105 (endoglin) ESAM (Ge and Butcher 1994; Nasdala et al. 2002). Several issues restrict their use for the ex vivo isolation of endothe- 
Fig. 5 Analysis of ex vivo-isolated LSEC after culture. LSEC were enriched by magnetic cell sorting using ME-9F1. a After in vitro culture over night morphology was assessed by phase contrast microscopy (bar $=50 \mu \mathrm{m})$. The uptake of AcLDL by LSEC was analyzed by b fluorescence microscopy (AcLDL, green; nucleus staining with Hoechst 33342 , blue) or $\mathbf{c}$ flow cytometry after counterstaining with ME9F1. d The expression of CD31, VE-cadherin and Meca32 antigen (bold line) was analyzed by flow cytometry at day 0 and 6 after in vitro culture. The respective isotypes were stained for negative control (thin line). Data shown are representative from least four independent experiments
A

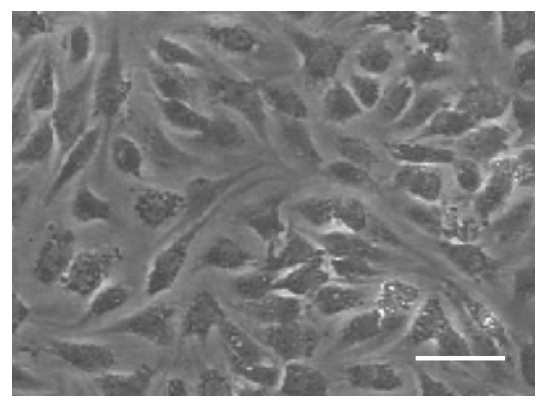

B

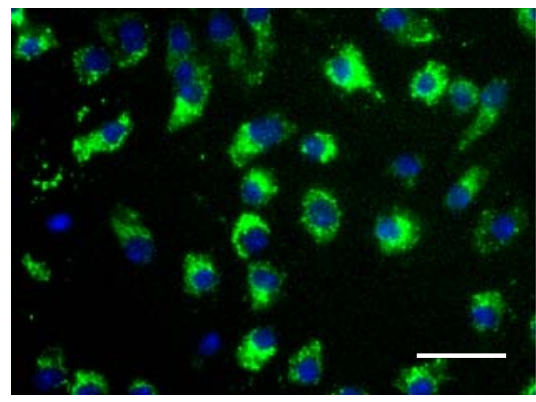

AcLDL, Hoechst 33342

C
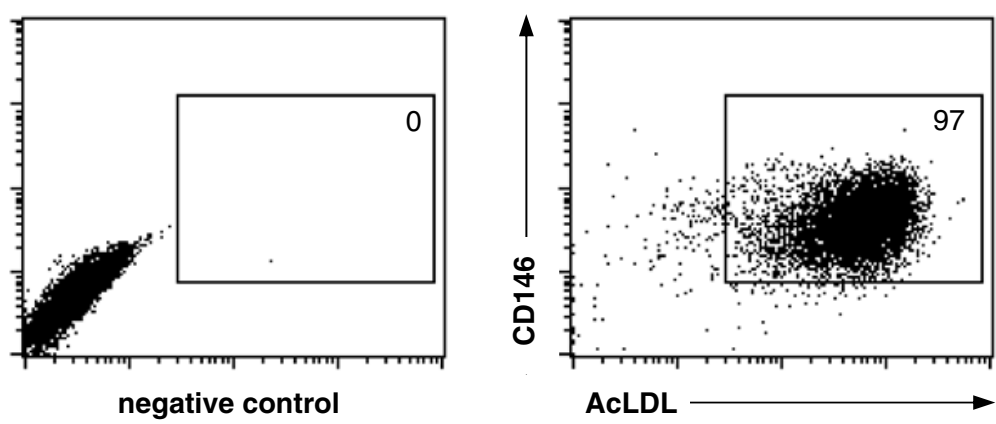

negative control

D
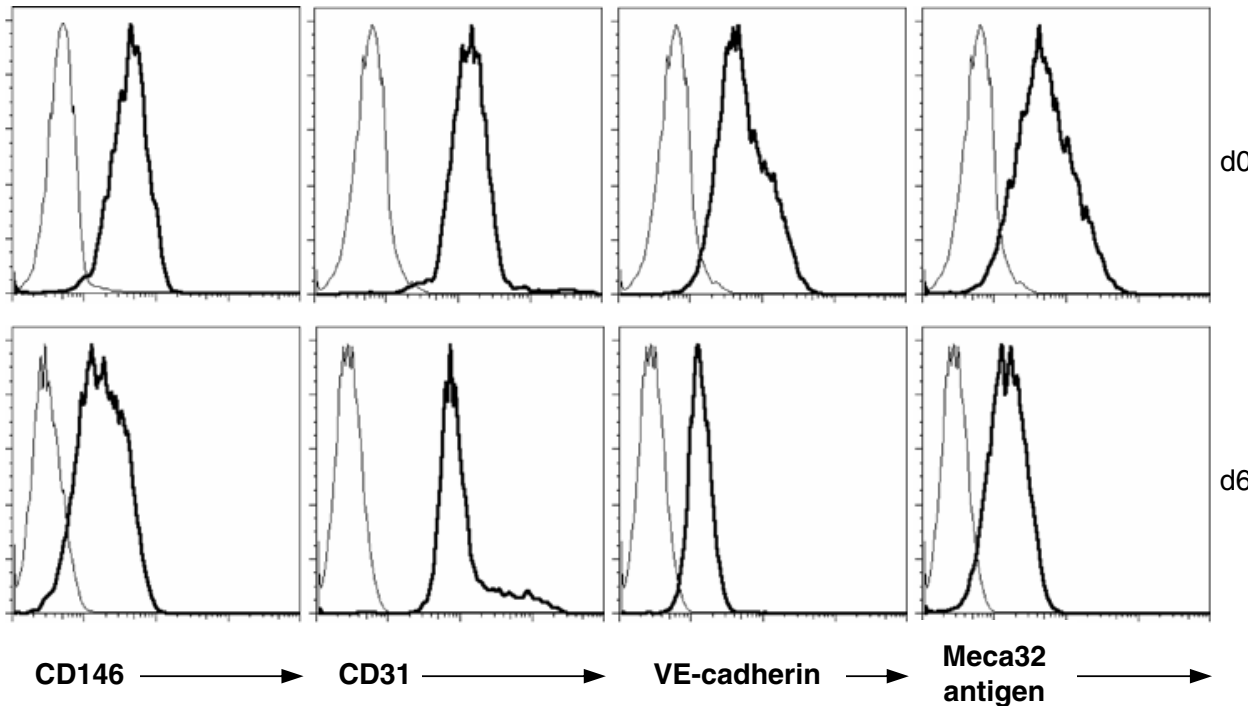

lial cells. These molecules are either not as specific (Bogen et al. 1992; Piali et al. 1993), are not highly expressed on all endothelial cells (Hallmann et al. 1995) or need to be detected intracellularly (Hoyer et al. 1973; Pusztaszeri et al. 2006).

The mab ME-9F1 described in this study detects all kinds of endothelial cells of blood vessels along the entire vascular tree in all murine organs investigated (e.g. lung, heart, kidney, liver, spleen, lymph node, intestine, brain, skin) without labeling lymphatic endothelium. It is useful not only for immunohistochemistry of cryopreserved and paraffin-embedded samples but also for Western blot and flow cytometry, the latter additionally attributing the epitope for ME-9F1 to the extracellular domain of CD146. Of the methods established for the ex vivo isolation of endothelial cells, out-growing from tissue sections is only practicable for larger murine vessels (Nicosia et al. 1994), density gradient centrifugation has to be followed by culture for a week to reach confluence (Veszelka et al. 2007) and isolation of liver endothelium by centrifugal elutriation requires significant technical equipment (Knook and Sleyster 1976). In contrast, magnetic sorting with the mab ME9F1 provides large endothelial cell numbers immediately after ex vivo isolation which makes it useful for, e.g., RNA 
Fig. 6 Endothelial growth and transendothelial migration of $\mathrm{T}$ cells after ME-9F1 binding to the endothelium. a sEND were treated with $50 \mu \mathrm{g} / \mathrm{ml} \mathrm{ME-9F1}$ or control antibody during culture. Phase contrast pictures taken after 24 and $48 \mathrm{~h}$ are representative for two independent experiments $(\mathrm{bar}=50 \mu \mathrm{m})$. b bEND5 grown to confluence on a transwell membrane were treated with ME-9F1 alone or with subsequent cross-linking with anti-rat antibody prior to the transendothelial migration assay. $\mathrm{T}$ cells were added to the upper chamber of the transwell and transmigrating $\mathrm{T}$ cells harvested and quantified after $90 \mathrm{~min}$. Data show one representative experiment out of two independent experiments with duplicate determination
A
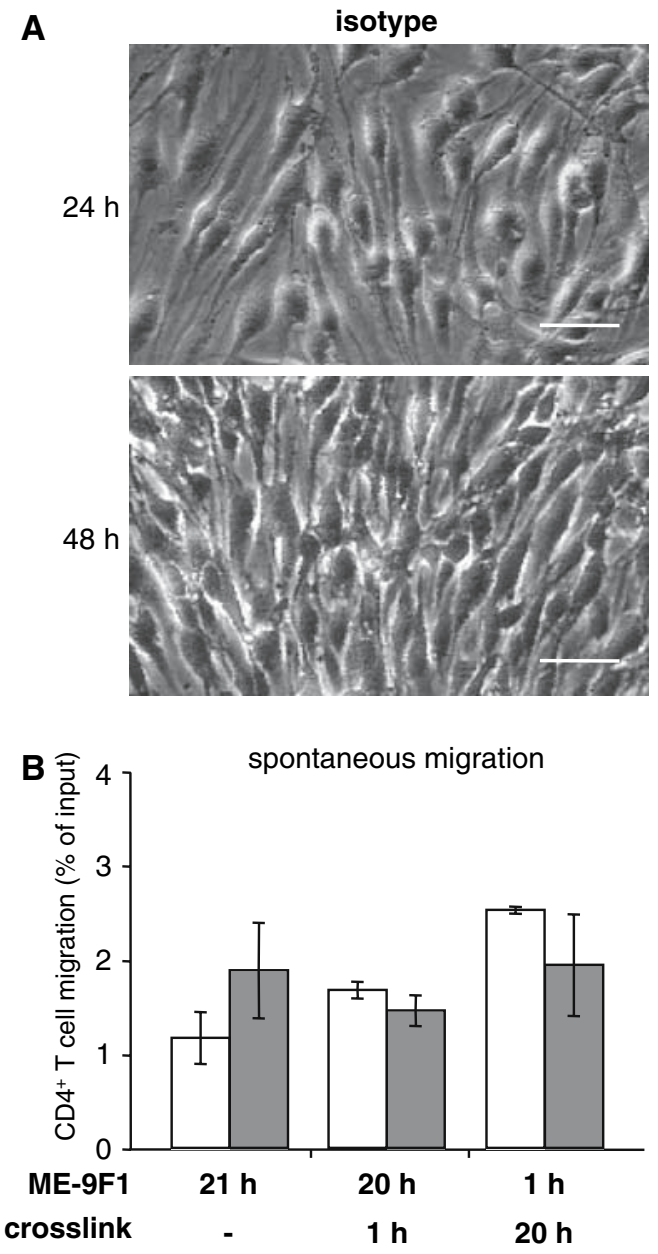
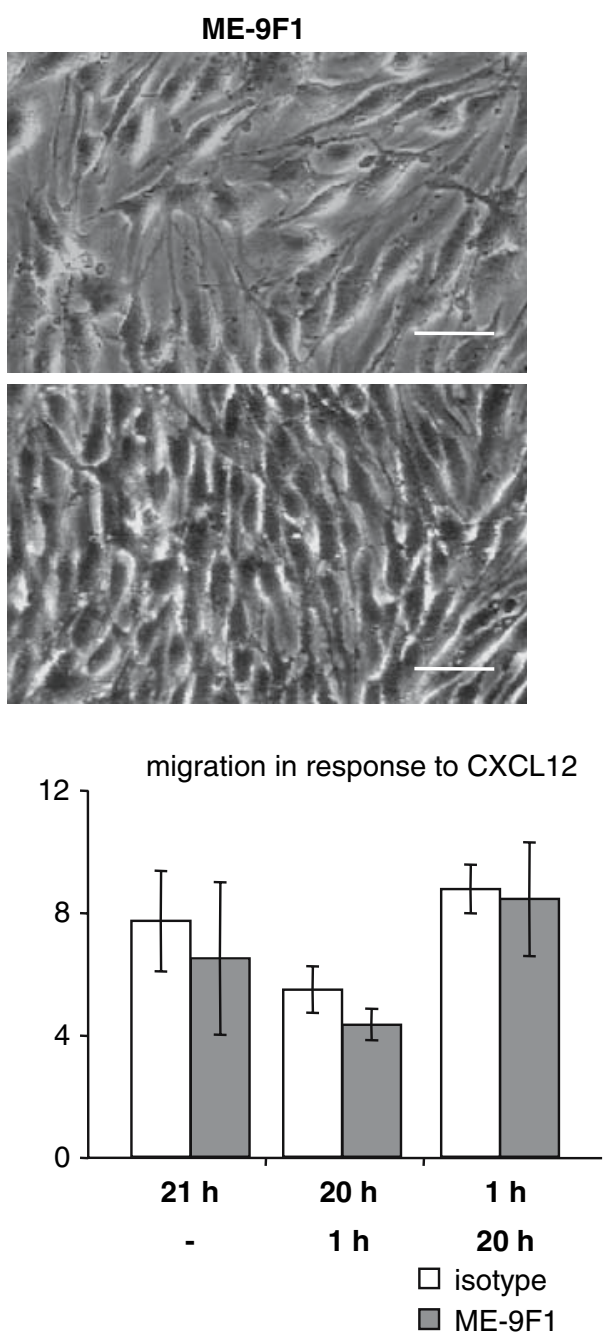

micro arrays. Directly labeled magnetic beads making the procedure easy and efficient are described for preparation of LSEC (Hegenbart et al. 2006). But sorting by CD146 is not limited to LSEC, as we and others could also enrich endothelial cells from other organs and even from tumors (Berger et al. 2005). Over night adhesion of enriched LSEC followed by thorough washing the cell layer results in higher purity with regard to the endothelial cells. The nonadherent fraction could be used for further investigations e.g. of CD146 $6^{\text {low }}$ NK cells.

The endothelial CD146 expression is regulated during monolayer formation and influences the paracellular permeability (Bardin et al. 2001; Solovey et al. 2001). Furthermore, CD146 plays a role in signal transduction. The outside-in signalling results in recruitment of the Src-family kinase FYN and the phosphorylation of FAK or paxillin, two proteins found in focal adhesion plaques. These results were obtained with an activating anti-human CD146 mab (S-Endo 1) (Anfosso et al. 1998, 2001). Here we demonstrated that ME-9F1 did not alter functional properties of murine endothelial cells. Neither the endothelial growth nor the transendothelial migration of $\mathrm{T}$ cells were increased or impaired by this mab. Also in $\mathrm{Ca}^{2+}$ influx assays (data not shown) we did not observe endothelial cell activation after preincubation with ME-9F1. This makes the antibody especially suitable for the ex vivo isolation of endothelial cells for functional studies.

In conclusion, our study describes a new tool for the detection and isolation of $\mathrm{CD}_{146^{+}}$cells and shows that CD146 is also in the murine system a component constitutive for all types of blood vessel endothelial cells. In addition, low levels were identifiable on NK cells, but not on NKT cells, T cells, follicular dendritic cells or smooth muscle cells. Recently, CD146 has also been described as a useful marker for circulating endothelial progenitor cells (Delorme et al. 2005). Although not tested so far in the mouse, ME-9F1 could allow transferring such studies into the murine system.

Acknowledgments The mab ME-9F1 was generated and initially characterized by R. Harder and B. Schütt in the group of A.H., Hamburg, Germany. We thank Simone Spieckermann, Charité, Berlin, Germany for technical assistance with the immunohistochemistry, Monika 
Schmid, MPI für Infektionsbiologie, Berlin, Germany for her help with the mass spectrometry experiments and Gretel Wittenburg, DRFZ, Berlin, Germany for testing the mab on follicular dendritic cells. This work was supported by the Sonderforschungsbereich 633, projects A8 (K. K. and A. H.) and Z1 (M.Z. and C. L.) of the Deutsche Forschungsgemeinschaft and by the Wilhelm Sander Stiftung, grant 1999.084.1 (J. J.).

\section{References}

Anfosso F, Bardin N, Frances V, Vivier E, Camoin-Jau L, Sampol J, Dignat-George F (1998) Activation of human endothelial cells via S-endo-1 antigen (CD146) stimulates the tyrosine phosphorylation of focal adhesion kinase p125(FAK). J Biol Chem 273:26852-26856

Anfosso F, Bardin N, Vivier E, Sabatier F, Sampol J, Dignat-George F (2001) Outside-in signaling pathway linked to CD146 engagement in human endothelial cells. J Biol Chem 276:1564-1569

Bardin N, Anfosso F, Masse JM, Cramer E, Sabatier F, Le Bivic A, Sampol J, Dignat-George F (2001) Identification of CD146 as a component of the endothelial junction involved in the control of cell-cell cohesion. Blood 98:3677-3684

Bardin N, Frances V, Lesaule G, Horschowski N, George F, Sampol J (1996a) Identification of the S-Endo 1 endothelial-associated antigen. Biochem Biophys Res Commun 218:210-216

Bardin N, George F, Mutin M, Brisson C, Horschowski N, Frances V, Lesaule G, Sampol J (1996b) S-Endo 1, a pan-endothelial monoclonal antibody recognizing a novel human endothelial antigen. Tissue Antigens 48:531-539

Bazzoni G (2006) Endothelial tight junctions: permeable barriers of the vessel wall. Thromb Haemost 95:36-42

Berger M, Bergers G, Arnold B, Hammerling GJ, Ganss R (2005) Regulator of G-protein signaling-5 induction in pericytes coincides with active vessel remodeling during neovascularization. Blood 105:1094-1101

Bogen SA, Baldwin HS, Watkins SC, Albelda SM, Abbas AK (1992) Association of murine CD31 with transmigrating lymphocytes following antigenic stimulation. Am J Pathol 141:843-854

Crispe IN (2003) Hepatic T cells and liver tolerance. Nat Rev Immunol 3:51-62

Delorme B, Basire A, Gentile C, Sabatier F, Monsonis F, Desouches C, Blot-Chabaud M, Uzan G, Sampol J, Dignat-George F (2005) Presence of endothelial progenitor cells, distinct from mature endothelial cells, within human CD146+ blood cells. Thromb Haemost 94:1270-1279

Doherty DG, Norris S, Madrigal-Estebas L, McEntee G, Traynor O, Hegarty JE, O'Farrelly C (1999) The human liver contains multiple populations of NK cells, T cells, and CD3+CD56+ natural T cells with distinct cytotoxic activities and Th1, Th2, and Th0 cytokine secretion patterns. J Immunol 163:2314-2321

Duff SE, Li C, Garland JM, Kumar S (2003) CD105 is important for angiogenesis: evidence and potential applications. Faseb J 17:984-992

Duijvestijn AM, Kerkhove M, Bargatze RF, Butcher EC (1987) Lymphoid tissue- and inflammation-specific endothelial cell differentiation defined by monoclonal antibodies. J Immunol 138:713-719

Galfre G, Milstein C (1981) Preparation of monoclonal antibodies: strategies and procedures. Methods Enzymol 73:3-46

Gao X, Kouklis P, Xu N, Minshall RD, Sandoval R, Vogel SM, Malik AB (2000) Reversibility of increased microvessel permeability in response to VE-cadherin disassembly. Am J Physiol Lung Cell Mol Physiol 279:L1218-L1225

Ge AZ, Butcher EC (1994) Cloning and expression of a cDNA encoding mouse endoglin, an endothelial cell TGF-beta ligand. Gene 138:201-206
Gotsch U, Borges E, Bosse R, Boggemeyer E, Simon M, Mossmann $\mathrm{H}$, Vestweber D (1997) VE-cadherin antibody accelerates neutrophil recruitment in vivo. J Cell Sci 110(Pt 5):583-588

Hallmann R, Mayer DN, Berg EL, Broermann R, Butcher EC (1995) Novel mouse endothelial cell surface marker is suppressed during differentiation of the blood brain barrier. Dev Dyn 202:325-332

Harder R, Uhlig H, Kashan A, Schutt B, Duijvestijn A, Butcher EC, Thiele HG, Hamann A (1991) Dissection of murine lymphocyteendothelial cell interaction mechanisms by SV-40-transformed mouse endothelial cell lines: novel mechanisms mediating basal binding, and alpha 4-integrin-dependent cytokine-induced adhesion. Exp Cell Res 197:259-267

Hegenbart S, Klugewitz K, Hamann A, Diehl L, Knolle P (2006) Efficient isolation of liver sinusoidal endothelial cells (LSECs) by immunomagnetic separation. MACS More 10:8-10

Hirata K, Ishida T, Penta K, Rezaee M, Yang E, Wohlgemuth J, Quertermous $\mathrm{T}$ (2001) Cloning of an immunoglobulin family adhesion molecule selectively expressed by endothelial cells. J Biol Chem 276:16223-16231

Hoyer LW, De los Santos RP, Hoyer JR (1973) Antihemophilic factor antigen. Localization in endothelial cells by immunofluorescent microscopy. J Clin Invest 52:2737-2744

Ishida T, Kundu RK, Yang E, Hirata K, Ho YD, Quertermous T (2003) Targeted disruption of endothelial cell-selective adhesion molecule inhibits angiogenic processes in vitro and in vivo. $\mathrm{J}$ Biol Chem 278:34598-34604

Klugewitz K, Blumenthal-Barby F, Schrage A, Knolle PA, Hamann A, Crispe IN (2002) Immunomodulatory effects of the liver: deletion of activated CD4+ effector cells and suppression of IFN-gammaproducing cells after intravenous protein immunization. J Immunol 169:2407-2413

Knook DL, Sleyster EC (1976) Separation of Kupffer and endothelial cells of the rat liver by centrifugal elutriation. Exp Cell Res 99:444-449

Lampugnani MG, Corada M, Caveda L, Breviario F, Ayalon O, Geiger B, Dejana E (1995) The molecular organization of endothelial cell to cell junctions: differential association of plakoglobin, betacatenin, and alpha-catenin with vascular endothelial cadherin (VE-cadherin). J Cell Biol 129:203-217

Lehmann JM, Riethmuller G, Johnson JP (1989) MUC18, a marker of tumor progression in human melanoma, shows sequence similarity to the neural cell adhesion molecules of the immunoglobulin superfamily. Proc Natl Acad Sci USA 86:9891-9895

Nasdala I, Wolburg-Buchholz K, Wolburg H, Kuhn A, Ebnet K, Brachtendorf G, Samulowitz U, Kuster B, Engelhardt B, Vestweber D, Butz S (2002) A transmembrane tight junction protein selectively expressed on endothelial cells and platelets. J Biol Chem 277:16294-16303

Nicosia RF, Villaschi S, Smith M (1994) Isolation and characterization of vasoformative endothelial cells from the rat aorta. In Vitro Cell Dev Biol Anim 30A:394-399

Piali L, Albelda SM, Baldwin HS, Hammel P, Gisler RH, Imhof BA (1993) Murine platelet endothelial cell adhesion molecule (PECAM-1)/CD31 modulates beta 2 integrins on lymphokine-activated killer cells. Eur J Immunol 23:2464-2471

Pickl WF, Majdic O, Fischer GF, Petzelbauer P, Fae I, Waclavicek M, Stockl J, Scheinecker C, Vidicki T, Aschauer H, Johnson JP, Knapp W (1997) MUC18/MCAM (CD146), an activation antigen of human T lymphocytes. J Immunol 158:2107-2115

Pusztaszeri MP, Seelentag W, Bosman FT (2006) Immunohistochemical expression of endothelial markers CD31, CD34, von Willebrand factor, and Fli-1 in normal human tissues. J Histochem Cytochem 54:385-395

Rohnelt RK, Hoch G, Reiss Y, Engelhardt B (1997) Immunosurveillance modelled in vitro: naive and memory $\mathrm{T}$ cells spontaneously migrate across unstimulated microvascular endothelium. Int Immunol 9:435-450 
Sers C, Kirsch K, Rothbacher U, Riethmuller G, Johnson JP (1993) Genomic organization of the melanoma-associated glycoprotein MUC18: implications for the evolution of the immunoglobulin domains. Proc Natl Acad Sci USA 90:8514-8518

Shih IM (1999) The role of CD146 (Mel-CAM) in biology and pathology. J Pathol 189:4-11

Siegmund K, Debes GF, Hamann A (2005) Chemotaxis assay: analysis of migration of lymphocyte subsets. Wiley-VCH, Weinheim

Solovey AN, Gui L, Chang L, Enenstein J, Browne PV, Hebbel RP (2001) Identification and functional assessment of endothelial P1H12. J Lab Clin Med 138:322-331

Sorokin L, Girg W, Gopfert T, Hallmann R, Deutzmann R (1994) Expression of novel 400- $\mathrm{kDa}$ laminin chains by mouse and bovine endothelial cells. Eur J Biochem 223:603-610

Vecchi A, Garlanda C, Lampugnani MG, Resnati M, Matteucci C, Stoppacciaro A, Schnurch H, Risau W, Ruco L, Mantovani A et al (1994) Monoclonal antibodies specific for endothelial cells of mouse blood vessels. Their application in the identification of adult and embryonic endothelium. Eur J Cell Biol 63:247-254

Veszelka S, Pasztoi M, Farkas AE, Krizbai I, Ngo TK, Niwa M, Abraham CS, Deli MA (2007) Pentosan polysulfate protects brain endothelial cells against bacterial lipopolysaccharide-induced damages. Neurochem Int 50:219-228

Wagner EF, Risau W (1994) Oncogenes in the study of endothelial cell growth and differentiation. Semin Cancer Biol 5:137-145

Wegmann F, Petri B, Khandoga AG, Moser C, Khandoga A, Volkery S, Li H, Nasdala I, Brandau O, Fassler R, Butz S, Krombach F, Vestweber D (2006) ESAM supports neutrophil extravasation, activation of Rho, and VEGF-induced vascular permeability. J Exp Med 203:1671-1677

Williams RL, Risau W, Zerwes HG, Drexler H, Aguzzi A, Wagner EF (1989) Endothelioma cells expressing the polyoma middle T oncogene induce hemangiomas by host cell recruitment. Cell 57:1053-1063

Yan X, Lin Y, Yang D, Shen Y, Yuan M, Zhang Z, Li P, Xia H, Li L, Luo D, Liu Q, Mann K, Bader BL (2003) A novel anti-CD146 monoclonal antibody, AA98, inhibits angiogenesis and tumor growth. Blood 102:184-191

Yokoyama WM, Seaman WE (1993) The Ly-49 and NKR-P1 gene families encoding lectin- like receptors on natural killer cells: the NK gene complex. Annu Rev Immunol 11:613-635 